\title{
Strange(r) Places: Collaborative Creativity in Real and Virtual Spaces
}

\author{
Tanya Perkins \\ Indiana University East \\ talperk@iue.edu
}

\begin{abstract}
In the writing classroom, collaborative learning often takes the form of coauthoring, peer workshops, or critique sessions. While these are useful, what other active-learning approaches might be effective, particularly in light of the range of media with which students are increasingly familiar? World building — creation of an alternative/speculative or futuristic land, world, or universe-offers an approach to fiction writing amenable to both creative collaboration and digital modalities. This article examines how a team-based world-building project in an advanced writing course leverages both physical and virtual space as creative collaborative environments by building upon the multiple modalities and genres through which many students already engage with fiction (video, online and/or fantasy role-playing games, horror, speculative and science fiction). With this approach, students in a seated class team up to create original alternative worlds in an online environment_including production of both digital and physical artifacts —within which their own (individual) stories are set. The result is movement between real and virtual space, as well as between shared creative acts and personal imaginative writing.
\end{abstract}

Keywords: collaboration, active learning, creative writing, world building, learning environments, social space, virtual space

In the physical classroom, courses on writing commonly promote collaborative learning through peer workshops or critique sessions. Since its early use in the University of Iowa graduate program in the 1930s, the workshop model has spread to undergraduate and even secondary classrooms. Typically under this model, the student whose work is critiqued remains silent while the rest of the class discusses the work's strengths and weaknesses. Despite its popularity, however, the workshop model's ability to foster creativity and innovation has been questioned. Students can end up with conflicting opinions that vary wildly in quality or, worse, feel pressured to conform to a group consensus. Coauthoring is another collaborative strategy, but it is less used; in fact, it is viewed somewhat suspiciously by writers, as Bishop and Starkey (2006) noted, referencing one national book contest's manuscript requirement that submitting writers assert they are sole author (p. 29). None of this is to suggest that these practices necessarily fail students or should be abandoned; rather, the goal of this article is to offer another take on the role of collaboration and more particularly, how a revised understanding of physical and virtual space can be employed to support collaboration and creativity.

As an active-learning strategy, collaboration has the potential to contribute to development of better problem solving, verbal expression, creativity, and engagement with challenges that speak to the kinds of so-called soft skills increasingly valued by 21st-century employers (Lin, Mills, \& Ifenthaler, 2016; Walker, 1996). Collaborative learning has been linked positively to a range of essential skills, including critical thinking, creativity, literacy, and "intercultural effectiveness" (Kilgo, Sheets, \& Pascarella, 2015; see also Huggins \& Stamatel, 2015). Moreover, because teamwork tends to shift attention away from the production of any one individual, it can potentially reduce performance stress within a supportive milieu (Archer \& Kelen, 2015). To the two collaborative forms mentioned thus far-peer workshops and coauthoring-Reither and Vipond (1989) added knowledge making: "We make our meanings not alone, but in relation to others' meanings, which we come to know through reading, talk and writing" (p. 862). Although their reference is to literary studies, I would argue that 
the same can be said about creative writing, as noted by Richardson (2016): "Artistic knowledge production occurs in a dynamic between independence and cooperation" (p. 2259).

\section{The Learning Challenge}

Yet for many students who are studying writing, collaboration as a creative strategy is not without unique tensions. The image of the solitary writer alight with personal genius owes much to 19thcentury romanticism (Inge, 2001). Writing does, in fact, often require alone time but that does not eliminate the need for what Becker (1982) called "networks of cooperation and assistance" (as cited in Richardson, 2016, p. 2260; see also Yancey \& Spooner, 1998). Richardson (2016) used that phrase to explain how artistic knowledge originates not from any single writer but from repeated interactions between individuals (p. 2260). Although she examined the practices of professional writers in a specific locale, I would argue that it has relevance for educational settings as well. If professional writers benefit from such interactive social "networks," then perhaps students might, too. Interestingly, Bishop and Starkey (2006) suggested that creative writing is particularly amenable to an approach that allows for both collaborative and solitary phases, noting that:

writing is not entirely a social activity, nor is it a provably solitary one. It is at once an act of individual cognition but also always an act of intellectual and social negotiation with other thinkers. We think and write in the presence of and as a result of our influences. (p. 33)

Aside from the creative benefits of such social negotiation, collaboration as a marketable skill is increasingly not just a bonus but a requirement in the eyes of many employers (Brown, Ernst, Clark, DeLuca, \& Kelly, 2017). As Johnson, Johnson, and Smith (1990) noted, "knowledge and skill are of little use if a student cannot apply them in cooperative interaction with other people" (as cited in Glasgow \& Bush, 1995, p. 32). As students have opportunities to practice collaboration in a variety of settings, including the creative writing classroom, they strengthen this valuable skill for practice beyond graduation.

Set against the backdrop of such benefits are 21 st-century students' own familiarity with a range of media and/or genres such as video, online and/or fantasy role-playing games, horror, speculative and science fiction, via laptops, tablets, and cell phones. These devices have become ubiquitous in the brick-and-mortar classroom, adding the dimension of virtual space to what traditionally had been limited to the square footage of the assigned classroom. World buildingcreation of an alternative/speculative or futuristic land, world, or universe-offers an approach to fiction writing amenable to both creative collaboration and digital modalities. The scope of the project creates room for multiple voices, facilitating collaborative use of physical classroom space along with shared virtual space. This happens when, for example, teams draw maps on whiteboards or cluster together at tables to argue about social structure or act out how a character walks or fights and then bring their creative decisions to life within a shared website, using images, sound, and written text. All of these offer avenues that harness teamwork as a springboard to individual and personal creative acts.

The interest in connecting the physical to the virtual is reflected in the early-21st-century evolution of interactive digital narratives, such as 34 North 118 West (Hight, Knowlton, \& Spellman, 2003, as cited in Rettberg, 2015, p. 177), which engages readers in moving through the streets of Los Angeles as they "read" the digital text. Reframing the reader-screen-physical setting triangle finds more intense expression in immersive virtual reality experiences, although engaged embodiment is not dependent on headsets and wands, as Rettberg (2015) explained: 
Readers are not necessarily sitting in a chair in front of a screen. They are just as likely to be moving through a narrative situated in physical space, or moving through the virtual space of an augmented reality environment...or encountering a digital narrative in a communal experience of a performance. (p. 178)

If true of readers, then it may also be true of writers as they create immersive fictional experiences. In particular, it is the idea of the communal experience in Rettberg's list that is of relevance to the collaborative, physical-digital navigation of world building as a learning activity.

At this point, it is useful to consider the term individualized collaboration, used by Ward \& Sonneborn (2009) to designate how players in virtual worlds create individualistic experiences for themselves within a shared online environment. They described how players of the video game Second Life individualize aspects of their graphical interface and personal representation, even while acting as a team member and problem solving with other players: "Personalization extends into the virtual space itself and to the user's experience of that space" (p. 219). Although empirical research is still needed, Ward and Sonneborn suggested that the power to customize one's experience of what is essentially a group interaction may possibly catalyze players to more imaginative and/or greater roles in the collaboration, thus strengthening group creativity overall (p. 219). Ward and Sonnemon's argument has interesting crossover to collaborative learning in considering how online spaces offer creative opportunities for both individuals and groups through the kinds of activities peculiar to digital environments. For example, freedom from the constraints of the brick-and-mortar world encourages "freewheeling thought" (p. 218), which in turn supports brainstorming, perhaps leading to ideas that otherwise would have been unattainable. Interestingly, one of the students in my world-building class referenced such a moment when he met with his team at a coffee shop to work on the website for their fictitious alternative world: "We were able to just go off on random tangents and even make weird and sometimes inappropriate jokes about our world to see what worked and what didn't." Thus it was the more informal space, encompassing both the physical and digital, that promoted creativity and expression, as I explain further.

There are two takeaways from Ward and Sonnemon's arguments that are particularly useful when it comes to learning spaces and collaboration. First, the environment in which collaboration takes place can have a direct effect on the nature of the collaboration, particularly with respect to the kinds of creativity that spring from it (see also Skill \& Young, 2002). In this regard, virtual space offers unique, creative possibilities, as Ward and Sonnemon argued. Second, collaboration can offer productive benefits to both the group and the group project but also to individuals, particularly within a digital environment. This occurs when individuals have scope to customize their contribution so that it not only supports the group goal but also has particular use or meaning to their own personal ends. The question remains, however, as to whether such individualization will actually have positive results for the group as a whole (Ward \& Sonnemon, 2009, p. 219). Nevertheless, the concept itself illuminates the learning potential of projects such as world building that offer both collaborative and individual components. Specifically, it is the idea that collaboration can be undertaken not solely with the goal of producing a team project but also as a springboard for an individual student's own project, in that the student is free to shape her or his contribution so that it can be used later to further that student's own personal creative work. Even if a student does not approach the contribution with that deliberately in mind, the give-and-take process of discussion may sow the seed for that student's own project, as is suggested by the case study that follows. 


\section{Solution Attempted}

ENG W401 is an upper-level course in the theory and practice of fiction writing and as such allows for considerable variation in content and pedagogy. As a teacher, my goal across creative writing courses is to engender students' initiative and creativity, to push them to try something new, maybe even uncomfortable. At the same time, I want to offer them content amenable to course learning goals but that they will also find engaging and motivating. World building as a route into all the fictional elements that I need to teach—character work, plot, setting, dialogue, thematic nuances, tension, and more-makes sense in that it builds upon the genres and modalities with which college students already engage, such as horror, science and fan fiction, fantasy role playing, video games, and movies. As a project, it opens the door for engagement in both physical classroom space and virtual space (see as a similar example, Rish \& Caton, 2011).

Course activities were organized to move between whole-class discussions of assigned readings by writers such as Tolkien and Gaiman, team-based world-building work, and short in-class writings. We also discussed theoretical and practical elements such as ideology, internal consistency, and the role of technology and/or magic. Students organized themselves into teams based on their preference for science fiction or fantasy; as a small class of just six students, it worked out evenly, with two teams of three students each. The teams collaborated on world building during the first part of the semester; during the second half, students independently wrote two short stories, one set in their own team's world and the second set in the other team's world. The world-building assignment consisted of six deliverables, each designed to draw upon a variety of skills and abilities, but all located within the team-set parameters of the group's alternative world. These included a wiki defining tangibles (weapons, food, housing, tools, etc.) and intangibles (religious beliefs, political system, historical events, reproductive practices, etc.); a map; a timeline; a speech delivered by a significant character (campaign speech, religious ceremony, artistic manifesto, etc.); an object of meaning; and a creative application (board game, visual art, or other creation).

Each team created a website as a common virtual space for the artifacts, using Wordpress, Wix, or another template-based free site, to which all members had administrative access and shared control. Teams were expected to have at least one laptop up and open during class work sessionssince students regularly had laptops with them, this did not pose a problem. Seamless transition between physical and virtual learning spaces was encouraged as teams held face-to-face discussions at the classroom's round tables, which would lead to writing together on their websites. These sessions had a fluidity to them as, for example, team writing might give way to members working individually on their own laptops, perhaps even physically moving to another table, only later to call out to each other, with one member leaping up to diagram something at the whiteboard, which would lead in turn to further collaborative revisions on the website.

Teams were encouraged to be creative in how they wanted readers to understand and navigate the world's site. So, for example, one team presented their site as a quasi-authentic historical archive documenting extraterrestrial control over 20th-century activities including an alternative timeline of historical events. The fictional elements of their world were overlaid onto actual history, mixing the real with the imagined in mockumentary style, using images, diagrams, text, and sound. The range of assignments allowed for considerable interpretation and differentiated individual work, so students could work on project components that best matched their own interests and strengths and that they could later leverage within their own stories, but even this independent work would need to be negotiated within the group to ensure that all work got completed. Such dialectic give-and-take opened up avenues of creative insight, not just for the collaborative project but also for students' own, independently written work. As one student noted: "As we chatted about what our world was like, it helped me to come up with the story I eventually used." 
As mentioned, class time was spent between discussions, short writing assignments, teamwork sessions, and, later in the semester, whole-class workshops of the stories students wrote on their own. Thus, although the short stories were independently written, they also received a measure of collaborative attention. Instead of remaining silent, as often is the case in traditional workshops, the student whose story was being considered led the discussion, asking questions and focusing the group's attention on the parts of the story where the student specifically wanted help. Taken together, these phases might be viewed holistically as "networks of cooperation and assistance," by means of which "artistic knowledge" is produced (Becker, 1982, as cited in Richardson, 2016, p. 2260). Discussions were particularly insightful when a student's story was set in the other team's world, letting them see how their world was being interpreted by a writer from the "outside."

As a face-to-face class, we met twice weekly in our assigned classroom, which had an open layout, extensive whiteboards covering the length of one long wall, and tables and chairs instead of fixed desks. Teams were able to take advantage of the ample, rounded tables, some at conventional table height and some at bar height, as collaborative workspaces and so naturally sat together, one team per table. As Cornell (2002) noted, "furniture is both tool and environment" (p. 33), and so tables became the common workspaces whereby students spread out texts, opened individual laptops and spoke face to face as they worked through the assignments. This environment supported students' freedom of expression and ability to learn from each other through spontaneous conversation and writing together on their team website. Similarly, the long whiteboards adjacent to the tables became the medium for capturing and illustrating ideas in process. These physical affordances enabled the ongoing real-time discussions that were part of the collaborative creation of the virtual and imaginative spaces. World elements such as physical geography or social hierarchy came into being through discussion, were sketched out on the whiteboards using dry erase markers, captured on students' cell phones, and then developed into virtual artifacts situated within their worlds' websites. The creative process thus traversed social, physical, and digital space within a classroom environment that supported "real and virtual collaboration" (Skill \& Young, 2002, p. 26).

\section{Qualitative Analysis of the Solution}

Following course completion and institutional review board exemption, a survey was distributed, aimed at assessing students' experience of the world-building assignment, collaboration, and the role of physical and virtual space. The class size was very small, just six students, of which four (or twothirds) responded to the survey. All respondents were white males; a larger and more varied demographic might offer additional insights. Nevertheless, small numbers can still be useful in providing a qualitative, contingent "understanding of particularity" characteristic of a unique situation (Baker, Edwards, \& Doidge, 2012, p. 30). Overall, surveyed evidence suggested that the collaboration worked to support students' creativity, as did specific aspects of the physical environment. Following is a discussion and analysis of student responses to key questions.

\section{How Useful Was the Collaboration Overall in Conceptualizing and Developing an Alternative Fictional World?}

Students were divided on this question, with half responding "useful to very useful" and the other two responding neutrally (and no one reporting that it was not useful). The two students who found the collaboration useful/very useful offered similar reasons- the team sessions enabled them to voice their thoughts and exchange ideas about what would go into their team's world. One student noted that "it enabled us to come up with things I would not have come up with myself... At the same time, I was able to bring my own strengths to the table — writing and imagination — and execute those parts 
of the project as well." Another stated that "it was helpful to articulate my ideas and talk about different ideas to go into the world." Two students identified lack of participation by a group member as an impediment, yet one of those two, who was neutral on the question of usefulness, described how he and the remaining group member were able to "work together well...to generate their world." Thus, it seems that unresponsiveness on the part of a team member was enough to pull down perceptions of usefulness of the collaborative sessions. This is understandable, given that the core of collaboration is reciprocal and evenly distributed participative effort. The second neutral student admitted that he just did not like teamwork, yet he still acknowledged that "teamwork and collaboration can be vital skills for writers."

\section{Which Did You Enjoy More-The Collaborative Sessions in Teams or Your More Solitary Sessions in Writing Your Own Stories?}

It might be expected that fiction writers would prefer independent writing, yet three of the four students were exactly in the middle, with only one student strongly preferring solitary sessions. One student summed up the productive tension between group work and individual creation: "A lot of good ideas came out of those sessions, but most of the real work happened individually." Another offered a similar appraisal: "I liked talking about the world and building it with my groupmates but I also really enjoyed attempting to write short stories in both my world and the other groups [sic]." A third offered an interesting shift, noting that while he "most enjoyed the writing," it was once the world building was well along that he began to look "more and more forward to writing." This suggests that collaboration had a catalytic effect on his personal desire to write. Only one student strongly preferred independent work sessions, "crafting the story in my own vision," as he put it, as the most enjoyable phase. This is not unexpected, given the highly personal nature of creative writing. Yet the fact that three of the four students were unable to definitely elevate either phase as more enjoyable than the other seems to suggest that creative work was occurring during both autonomous and collaborative sessions, supporting Richardson's (2016) assertion that "artistic knowledge production occurs in a dynamic between independence and cooperation" (p. 2259). There is no question that solitary intervals are critical to writing a short story, when imaginative impulses and reflection can let a writer's "own vision," to repeat the student's phrase, productively develop. At the same time, these findings, taken together, offer an example of how shared experience may be as much a part of what Richardson called "the geographies of creative writing" as are periods of isolation (p. 2260).

\section{What Was the Most Useful or Enjoyable Aspect of the Collaborative World-Building Assignment for You as a Writer? What Was the Least Useful or Enjoyable?}

Again, two of the four students identified brainstorming as the most useful aspect. Noted one student:

I really appreciated seeing how to write and create the different aspects of the world, and coming up with a number of different things that I never thought of before as being really important to the world, such as what the characters believed, or ate, and how they lived.

Another described "seeing how other students did their writing and comparing my own writing to their and to other works we read in class." Interestingly, a third student described writing a story set in the other team's world as the most enjoyable part of the collaboration. All three responses speak to what Richardson (2016) described as "forms of shared experience" making up the landscape of creative writing (p. 2260). In the class, this encompassed talking about elements of fictitious worlds, 
discussing the works of published authors, and studying the products of both collaborative and independent work sessions. In identifying the least useful or enjoyable aspect, students' responses varied. One student disliked having to create a website with his team, although admitted that "it wound up being much better than I originally thought." Another disliked the map assignment, although recognizing its importance to the world-build. A third mentioned, again, lack of participation by a team member.

\section{Did the Teamwork Sessions Help You Generate Ideas for Your Own Stories (Either During the Course or Afterward)?}

Three of the four students confirmed that the collaboration helped them with their own ideas, with only one responding negatively. "The sessions definitely helped develop ideas for my stories because we were able to fully understand the world and the different aspects in play," said one student. Another noted, "I found the teamwork sessions extremely useful for crafting my own story for our world. As we chatted about what our world was like, it helped me to come up with the story I eventually used." This suggests the potential of a collaborative dynamic to spark both pragmatic knowledge ("understand...different aspects") and more personal, creative knowledge ("develop ideas") that students could later use for their own stories during solitary writing sessions. Working together, teams generated nuts-and-bolts facts about their world, which were then captured in their website. The websites functioned as a kind of digital reservoir, from which students could later draw useful information as needed when working on their own at home or other off-campus sites, mixing and/or reinterpreting it within their own fiction.

\section{How Useful Was the Physical Environment to Your Overall Learning and/or Creative Experience? To the Teamwork Sessions?}

Three of the four students described the physical environment-specifically, the open space of the classroom, ample tables, and long whiteboards - as being very helpful. "It was great for both the class and teamwork sessions," one student said. "I utilized the whiteboard while creating my group's world, filling it out to put things in certain categories." Another student noted, "During the first group session, we had the entire [whiteboard] covered with ideas and details of our world. We then took a picture of it to be able to refer back... It guided us throughout the entire project." As students created their alternative worlds on their laptops, the table where they gathered as a team became, for the duration of each class session, their own "team space." As their instructor, I respected those spaces, not interjecting myself or my opinion-although their sometimes avid conversations were within earshot - unless invited. Students were able to maintain control of both their team's virtual space, the website, and the physical space that they occupied within the classroom. A third student, while also confirming the highly useful physical environment of that particular classroom, mentioned the coffee shop where his team would meet for additional sessions: "The somewhat informal setting of the class and then later, the local coffee shop where my team met up to brainstorm really helped." Thus both the classroom and off-campus site(s) came to fit what Skill and Young (2002) described as "meaningful, student-controlled learning communities" (p. 25). In their discussion of individualized collaboration, Ward and Sonnemon (2009) argued that creativity cannot be entirely separated from the environment in which people find themselves. Interestingly, as quoted earlier, this same student described the team sessions in the coffee shop as "organic and fun" because they felt free to "go off on random tangents and even make weird and sometimes inappropriate jokes about our world to see what worked and what didn't." Thus, although Ward and Sonnemon were making specific application 
to virtual space, the same can be said for physical spaces as well and-more interestingly-the affordances of physical and virtual space together.

\section{Reflection on the Implications}

While students overall found the world-building project to be an enjoyable creative experience, this was the first time I taught this version of the course, and so it was not without its challenges. Lack of participation and/or initiative on the part of one or more students created difficulties for both teams, a fact many students may rediscover as part of a future workplace team. Honest instructor-student conversations can help identify root problems, while grading flexibility may alleviate anxiety on the part of students who fear they will be penalized unfairly. The next time I teach this course, instead of trying to solve the problem, it may be more productive to help students develop work-around strategies that they can draw on when this inevitably crops up again in future courses and/or jobs. To bolster students' extrinsic motivation to work together, the world-building project was originally intended to result in a single, collective grade for each team, but when it became clear that this would not be fair due to lack of participation by a team member, the assignment was adjusted so that students each received their own grade. In the future, a self-evaluation for team members may be added partway through the project so that students can reflect on their role and the nature and extent of their participation. This would further assist in fair and authentic grading. A separate issue surrounded the configuration of the classroom chairs, which caused difficulties for a student of size who commented on the need for "sturdier, padded chairs for the sake of my tailbone." As the American population becomes physically larger, institutions need to accommodate a range of sizes and this should be reflected in such environmental elements as chairs with more adjustments, moveable (or no) armrests, and larger frames.

Aside from these observations, the world-building course demonstrated that, just as creative knowledge does not rise from a void, neither does productive collaboration. The production of collaborative work, as well as the nature and progress of collaboration, is bound up by the material spatial affordances in which it occurs. How students act and the range of actions optionable to them are closely dependent on the nature of the space in which they find themselves (Cornell, 2002). Students and educators are familiar with classrooms filled with rows of bolted-down chairs facing forward, situating students as uniformly passive listeners, an artifice left over from the medieval university that suffered from a scarcity of books. By the start of the millennium, as the Internet became ubiquitous, educators were recognizing the need for a blended model of both digital and physical spaces that together would enable "interactive and learning-by-doing strategies" (Skill \& Young, 2002, p. 24).

With that in mind, the design of the world-building course facilitated interaction between social, digital, and physical space by making each equally necessary and relevant to the success of students' work - and, more importantly, by seeking to make each team member necessary and relevant to the success of the project. The world-building project itself was intended to be too much work for any one student; to accomplish the project, students had to figure out how to work together across social/physical and digital spaces, and this they did, for the most part. For example, one team cowrote and produced a podcast set in their alternative world, in which all three members took on character roles to debate the presence of extraterrestrials, which they then posted to their website. That production which was highly successful, could not have been completed without interaction across social space (the give-and-take of figuring out their roles), physical space (finding a physical setting conducive to rehearsing and recording the podcast), and digital space (editing and importing the recording to their website, with appropriate headings, visuals, and textual introduction). No one element was removable without the experience being diminished or even made impossible. 
In looking at assessment, grades trended higher on students' first individually written story when compared to the same assignment in the advanced fiction course taught 2 years earlier, which had a similar student demographic and enrollment, but without the collaborative world-building focus. (Both versions of the course also included a second story assignment, but the grading method differed, preventing comparison.) Higher scores may be a result of students working together on their created worlds for an extended period of time prior to starting to write their own stories. This extra time spent on collaborative creative activity, immersion in their alternative worlds, and hammering out ideas may have better prepared students for their own independent writing, so that when they confronted the blank page to begin their own stories, they had more material to draw from and a heightened mental image of characters and setting, leading to better use of imagery, plot, and other elements. However, it is difficult to make a determination without additional data. Interestingly, students' own perceptions of their learning, as indicated in the course evaluations, were also higher compared to the same advanced fiction class taught 2 years earlier. This includes scores for the following (on a 1 to 5 scale, with 5 signifying the strongest agreement): Course assignments contributed to my learning (4.8 vs. 4.2); the level of intellectual challenge was high (4.5 vs. 4.0); found the text course material useful (4.8 vs. 3.6). More surprisingly, however, was the increase in the following: The instructor respected students and their ideas (5.0 vs. 4.0). This last score suggests that the emphasis on collaboration across physical and digital spaces affected not just the students but me, the instructor, as well.

In making an argument about political/urban spaces, Henri Lefebvre (1991) asserted that "new social relations demand a new space" (p. 59). In considering the tenets of both critical pedagogy and active learning, which together work to change the social order of the classroom in favor of a "student-controlled learning community," to return to Skill and Young's (2002) term, it would then seem reasonable that the way one thinks about learning space-the nature of what constitutes that space-would have to be renovated. What implications might this have? For one, the need to move from considering space on the basis of either/or (as in either physical space or virtual space) to that of both/and (see Bishop \& Starkey, 2006, p. 33). Almost two decades ago, Skill and Young (2002) called for "a learning environment that pushes us to work at the intersections of virtual and physical spaces" (p. 31). As prescient as this was, perhaps a reevaluation of the intersection metaphor is worthwhile. In the middle of a physical roadway intersection, the two streets merge. It becomes impossible to differentiate one street from the other where the boundaries are swallowed by the new space created by the blending of the two. Similarly, the intersection of virtual, physical, and social space creates a new hybrid space where no one part of the tripartite learning space can be identified in isolation, without necessary reference to and reliance on the other two parts.

In the world-building course, social space was produced through the cooperative actions of team members creating virtual artifacts within the digital space of their websites. Those collaborative websites then became raw material for individually written stories, which, in turn, were read and discussed during group workshop sessions led by the student writer. The collaborative digital space was facilitated by physical spaces - the long whiteboard where teams diagrammed their ideas, the round tables where they spread out their laptops and conversed face to face, the informal setting of the coffee shop where one team convened. Thus, the learning experience as a sustained event was dependent on the dynamic between collaborative and independent work within the confluence of all three kinds of space. With this view, space is understood as not just the walls and tables of a physical classroom or the digital spaces of a website or even the social configuration of student teams but as all of these taken together, each necessary and interdependent on the presence of the other two to create a productive learning environment for both collaborative and independent creativity. 